\title{
Effects of Curcumin on Biological Behavior and NF- $\kappa$ B/TNF- $\alpha$ Pathway in Mice with Metastatic Bone Pain of Breast Cancer Induced by Walker 256 Cells
}

\author{
Aijun Ji1 ${ }^{*}$, Mingchen Zhu ${ }^{2}$ \\ ${ }^{1}$ Pain Department, Jiangsu Cancer Hospital (Institute of Jiangsu Cancer Prevention and Control, Cancer Hospital Affiliated to \\ Nanjing Medical University), Nanjing, China \\ ${ }^{2}$ Laboratory Department, Jiangsu Cancer Hospital (Institute of Jiangsu Cancer Prevention and Control, Cancer Hospital Affiliated \\ to Nanjing Medical University), Nanjing, China \\ Email: *jajoffice@163.com
}

How to cite this paper: Ji, A.J. and Zhu, M.C. (2020) Effects of Curcumin on Biological Behavior and NF- $\kappa$ B/TNF- $\alpha$ Pathway in Mice with Metastatic Bone Pain of Breast Cancer Induced by Walker 256 Cells. Journal of Cancer Therapy, 11, 339-350. https://doi.org/10.4236/jct.2020.116028

Received: May 7, 2020

Accepted: May 26, 2020

Published: May 29, 2020

Copyright $\odot 2020$ by author(s) and Scientific Research Publishing Inc. This work is licensed under the Creative Commons Attribution International License (CC BY 4.0).

http://creativecommons.org/licenses/by/4.0/

\begin{abstract}
Background. The active ingredient curcumin of traditional Chinese medicine was selected as the research object to investigate the possible mechanism of breast cancer metastatic bone pain in mouse walker 256 cells and the effect of curcumin on the NF- $\kappa \mathrm{B} / \mathrm{TNF}-\alpha$ pathway in order to provide a new idea for clinical treatment of breast cancer metastatic bone pain. Methods. By establishing an animal model of breast cancer bone metastasis in walker 256 cells, the biological behavior of nude mice was observed on the $8^{\text {th }}$ day after successful modeling. Meanwhile, the low dose group, middle dose group and high dose group of mice were given $15 \mathrm{mg} / \mathrm{kg}, 25 \mathrm{mg} / \mathrm{kg}, 50 \mathrm{mg} / \mathrm{kg}$ of curcumin solution intraperitoneally in 21 days, and the right cavity bone and spinal cord distended in mice (L4-L6) tissues were used to detect related factors, Immunohistochemical method was used to detect c-fos in spinal cord. Expression levels of RANK, NF- $\kappa$ B and TNF- $\alpha$ were detected by RT-PCR and Western blot. Meanwhile, serum levels of Cox2, il-6, leukotriene and PGE2 were detected. Results. Observing the biological behavior index of nude mice, we found that the mechanical pain and thermal pain threshold decreased $(\mathrm{p}<$ $0.05)$, and the cold pain and spontaneous pain scores increased significantly $(\mathrm{p}<0.05)$. After group study, the expression of $\mathrm{c}$-fos in the cancer pain model group was significantly higher than that in the normal control group $(\mathrm{p}<$ 0.05 ), and with the increase of curcumin dose, the expression of c-fos in the high dose group was significantly lower than that in the solvent model group $(\mathrm{p}<0.05)$. The expression of RANK, NF- $\kappa \mathrm{B}$, TNF- $\alpha$ was higher than that of
\end{abstract}


the normal control group and decreased gradually with the increase of curcumin dose, among which the expression of high dose group was significantly lower than that of solvent group ( $\mathrm{p}<0.05$ ). RANK, NF- $\kappa \mathrm{B}$, TNF- $\alpha$ protein expression was higher than that of normal control group and gradually decreased with the increase of curcumin dose. The levels of Cox2, IL-6, leukotriene and PGE2 in serum decreased with the increase of curcumin dose, and the high dose group decreased significantly $(\mathrm{p}<0.05)$. Conclusions. On the $8^{\text {th }}$ day after the success of the animal model of breast cancer bone metastasis in Walker 256 cells, abnormal biological behaviors such as heat pain, cold pain sensation and spontaneous hyperalgesia were observed. Further studies have found that the increased expression of rank on osteoclasts induced up-regulated expression of NF- $\kappa \mathrm{B}$ and $\mathrm{c}$-fos, induced expression of TNF- $\alpha$ gene, and could induce synthesis and release of leukotriene, PGE2 through direct activation of cyclooxygenase, inflammatory media IL-6 cascade reaction, resulting in pathological pain and hypersensitivity. Traditional Chinese medicine active ingredient curcumin could reduce RANK expression of osteoclast, inhibit cell NF- $\kappa$ B and spinal cord $c$-fos activity, reduce TNF- $\alpha$ expression, inhibit Cox 2 activity, and reduce the synthesis and release of inflammatory factors leukotriene and PGE2, thus exerting its analgesic effect, which provides new ideas and methods for clinical treatment of metastatic bone pain in breast cancer.

\section{Keywords}

Curcumin, Breast Cancer, Metastatic Bone Pain, Mice, Biological Behavior, NF-B/TNF- $\alpha$

\section{Introduction}

Breast cancer was one of the most common malignant tumors in women, and most patients with advanced breast cancer were often accompanied by bone invasion, which could easily cause intractable bone pain, pathological fracture and a series of bone-related events. Curcumin was the main active component extracted from the roots of turmeric, which had the effects of anticoagulant, hypolipid, antioxidation, anti-inflammatory, anti-rheumatic and anti-tumor [1]. Meanwhile, curcumin had certain effects on the physiological function, pathological process and bone metabolism of the nervous system, and could alleviate the inflammatory reaction, inhibit the peripheral or central sensitization of chronic pain [2]. In this study, the animal model of metastatic bone pain caused by breast cancer in Walker 256 cells was established. Curcumin, an active ingredient of traditional Chinese medicine was selected as the research object, and the biological behavior changes of model animals were dynamically monitored. The expression of RANK, NF- $\kappa$ B, TNF- $\alpha$ and related factors in upstream and downstream were detected by immunohistochemistry, RT-PCR and Western blot, so as to explore the possible mechanism of metastatic bone pain in breast cancer and the effect of curcumin intervention. It will provide a new idea and method 
for clinical treatment.

\section{Methods}

\subsection{Cell Culture and Injection of Tumor Cells into Tibia}

Walker 256 cells were cultured in RPMI1640 medium containing 10\% calf serum and cultured at $37^{\circ} \mathrm{C}$ for routine passage. When the cultured Walker 256 cells were in logarithmic growth phase, the cells were collected and injected into the right tibia of nude mice. Each animal was inoculated with 20 ul, including $2 \times$ $10^{6}$ cells, 5 nude mice were injected, and the heat inactivated Walker 256 cells were injected as negative control.

\subsection{Biological Behavior Observation}

The behavior of nude mice was observed on the $8^{\text {th }}$ day, and the PWT value was less than $6 \mathrm{~g}$, and the mechanical pain threshold was stable, that is to say, the model was successful. The main observation indexes were as follows: 1) Determination of paw withdrawal threshold (PWT): Mechanical hyperalgesia was measured by foot contraction reaction stimulated by Von Frey fiber filaments. From the $8^{\text {th }}$ day of modeling, once every other day, four kinds of vonFrey fine fibers $(1 \mathrm{~g}, 2 \mathrm{~g}, 6 \mathrm{~g}$ and $15 \mathrm{~g}$ ) were used to stimulate the left middle plantar of mice. The foot contraction reaction of mice was observed. Each animal was tested 5 times per fiber, at least 2 minutes between the two tests. The percentage of foot contraction response of animals to vonFrey fiber stimulation was $5 \times$ $100 \%$. 2) Determination of paw withdrawal latency (PWL): By using the method of hot plate experiment, the hot plate was set to $(48 \pm 0.1)^{\circ} \mathrm{C}$, and then the mice were put into the glass lattice on the hot plate. The legs of the mice were lifted, and the latent period of escape and licking of the feet was used as the pain threshold. The average value of three times was calculated at an interval of $10 \mathrm{~min}$, and the result was hyperalgesia score. 3) Determination of cold pain sensitivity: cold plate test and acetone low temperature test were commonly used. The abnormal cold pain behavior of bone cancer pain model animals can be judged by the determination of cold stimulation hyperalgesia. 4) Observation of spontaneous pain behaviour: the spontaneous hyperalgesia behavior in the model of bone cancer was determined by spontaneous hyperalgesia behavior. Mice were placed on a smooth platform to walk freely, and the walking posture, side landing, and foot load of tumor-bearing nude mice were observed for scoring (between 0 and 3 points). 0 : normal action; 1 point: mild claudication of the hind limb of the inoculation side, can be used normally but relatively insignificant; 2 : the degree of claudication of the hind limb on the inoculation side was between 1 and 3; 3: severe lameness of the hind limb on the inoculation side or inability to reach the ground when the hind limb was walking.

\subsection{Grouping and Administration}

After screening the basic pain threshold, the mice were randomly divided into 
five groups: normal control group, solvent group, low-dose group, middle-dose group, high-dose group, from $8^{\text {th }}$ day, mice were given $15 \mathrm{mg} / \mathrm{kg}, 25 \mathrm{mg} / \mathrm{kg}, 50$ $\mathrm{mg} / \mathrm{kg}$ curcumin solution twice a day in the low-dose group, medium-dose group and high-dose group. The solvent group was given intraperitoneal injection of equal volume solvent ( $7 \%$ DMSO $+2 \%$ TW80) twice a day. No intervention was performed in the normal control group. Naked mice were given a normal diet during administration.

\subsection{Histology Research}

On the $21^{\text {st }}$ day, the mice in each group were fixed by intraabdominal injection of $10 \%$ chloric acid hydrate, then the blood was taken from the abdominal aortic upward, then perfused with a large amount of normal saline, and the fixed tissue was continuously perfused with polymethyl yeast after perfusion. After perfusion, the right cavity bone and spinal cord lumbar enlarged segment (L4 - L6) of the mice were taken, and the following experiments were carried out: 1) The expression of c-fos in spinal cord by immunohistochemistry. The spinal cord segment of L4 - L6 was quickly fixed in 4\% paraformaldehyde and embedded in conventional paraffin. The slice thickness was $4 \mu \mathrm{m}$. The spinal cord sections were treated with routine dewaxing, then incubated with $3 \% \mathrm{H}_{2} \mathrm{O}_{2}$ for $10 \mathrm{~min}$, then boiled in citric acid buffer $(\mathrm{pH}=7.2)$ for $10 \mathrm{~min}$. After blocking $10 \mathrm{~min}$, the excess serum was removed and incubated at $4^{\circ} \mathrm{C}$ for $15 \mathrm{~h}$. After $15 \mathrm{~h}$, the second antibody and SP were added and then stained with $\mathrm{DAB}$ and hematoxylin, transparent with xylene, and finally sealed with neutral gum. The positive reaction of c-fos was observed under light microscope and the images were collected. 2) mRNA extraction and detection of RANK, NF- $\kappa$ B and TNF- $\alpha$ by RT-PCR. On the $21^{\text {st }}$ day of the experiment, the rats were killed after deep anesthesia with chloral hydrate (10\%). The spinal cord corresponding to the L4 - L6 segment of lumbar vertebrae was peeled off quickly, and the tissue homogenization was carried out under ice bath condition and RNA was extracted. The samples were divided into control group, $15 \mathrm{mg} \mathrm{kg}, 25 \mathrm{mg} \mathrm{kg}$ and $50 \mathrm{mg} \mathrm{kg}$ groups. The extraction method of total RNA was carried out according to the instructions on the kit. The RNA samples were diluted with sterilized water 100 times or the appropriate multiple was taken to determine the quality of RNA at the absorption values of $260 \mathrm{~nm}$ and $280 \mathrm{~nm}$. The concentration of RNA was calculated according to the following formula: the concentration of RNA $=$ OD $260 \times$ dilution multiple $\times 0.04 \mu \mathrm{g} / \mu \mathrm{l}$, and the OD260/280 value between 1.8 and 2.1 was regarded as the purity of the extracted RNA. The amplification conditions were as follows: immediately after $65^{\circ} \mathrm{C}$ water bath for $5 \mathrm{~min}$, the mixture of reagents was added, the mixture was mixed by shock, then centrifuged at $37^{\circ} \mathrm{C}$ water bath for $60 \mathrm{~min}$, water bath at $-95^{\circ} \mathrm{C}$ for $5 \mathrm{~min}$, preserved at $-20^{\circ} \mathrm{C}$ for reserve, cDNA polymerase continuous reaction (PCR) amplification parameters, predenaturation at $95^{\circ} \mathrm{C}$ for $5 \mathrm{~min}$, denaturation at $95^{\circ} \mathrm{C}$ for $30 \mathrm{~s}$, extension at $72^{\circ} \mathrm{C}$ for $30 \mathrm{~s}, 35$ cycles and terminal extension at $72^{\circ} \mathrm{C}$ for $10 \mathrm{~min}$. The amplified products were 
detected by $1.7 \%$ agarose gel electrophoresis. The results were quantitatively analyzed by gel imaging and analysis system and corresponding software. The PCR primer sequences were as follows: GAPDH primer (133 bp), Sense primer: 5-ACAACTTTGGCATTGTGGAA-3, Antisense primer: 5-GATGCAGGGATG ATGTTCTG-3; NFKB-p65 primer (137 bp), Sense primer: 5-GAGATCCTGCTT CCATCTCC-3, Antisense primer: 5-CACTGCTTTGGATCAAGGTG-3; TNF- $\alpha$ primer (133 bp), Sense primer: 5-GACAGTGACCTGGACTGTGG-3, Antisense primer: 5-TGAGACAGAGGCAACCTGAC-3; RANK primer (126 bp), Sense primer: 5-AAGGGTGACATCATCGTGGT-3, Antisense primer: 5-AAAGGAG TCTCTGTGTGCCA-3. 3) Detection of RANK, NF- $\kappa$ B and TNF- $\alpha$ by Western blot. The spinal cord corresponding to L4 - L6 segment of lumbar vertebrae was isolated and homogenized under ice bath. 10\% SDS-PAGE electrophoresis was carried out for $3 \mathrm{~h}$, and then added NF- $\kappa \mathrm{B}$, TNF- $\alpha$, RANK-antibody, incubated at $4^{\circ} \mathrm{C}$ for $12 \mathrm{~h}$, then added HRP-labeled second antibody, incubated at room temperature for $2 \mathrm{~h}$, The $\mathrm{DAB}$ color was stained for $10 \mathrm{~min}$ before the images were collected. The target band was determined by image analysis software Image pro plus 6.0, and the integral optical density value (IOD) of the target band was used as the expression of NF- $\kappa$ B, TNF- $\alpha$ and RANK. 4) Serum levels of Cox 2, IL-6, leukotriene and PGE 2 were measured.

\subsection{Statistical Analysis of Data}

After all data were recorded in EXCEL and reviewed, SPSS13.0 software was used for statistical analysis. $\mathrm{p}<0.05$ was considered as the level of significance test for all statistical analysis. 1) Measurement data. Descriptive statistical indicators, such as frequency, composition ratio, mean and standard deviation, were used for general characteristic data. For the comparison between groups, the normality test was performed first. For normal distribution, $t$ test was used for comparison between two groups, and a nova was used for comparison between multiple groups. Homogeneity test of variance was required before. The rank-sum test is used for those that do not conform to the normal distribution or have uneven variances; 2) Counting data. Chi-square test or Fisher exact probability method is used to compare the rate or composition ratio.

\section{Results}

\subsection{Physicochemical Properties of Curcumin}

Curcumin has a molecular formula of C21H2006, a molecular weight of 368.37 $\mathrm{g} / \mathrm{mol}$, a melting point of $183^{\circ} \mathrm{C}$ and crystalline. Curcumin was a rare pigment in the botanical world with diketones, consisting of two ortho-methylated phenols and a beta-dione. The structure of beta-dione has an enol-ketone interconversion structure, but the spectral structure proves that curcumin mainly exists as enol in solid state and solution [3]. The keto-ol interconversion isomerism is shown in Figure 1. Curcumin was extremely insoluble in water but soluble in organic solvents and more stable under acidic and neutral conditions. Under al- 
kaline conditions, curcumin was highly unstable, easily decomposed, and appeared yellow or $\tan [4]$.

\subsection{Observation of Biological Behavior}

After detecting the mechanical pain, heat pain, cold pain and spontaneous pain in nude mice, it was found that the mechanical and thermal pain of rats were significantly decreased after the Walker 256 cells were inoculated $(\mathrm{p}<0.05)$, and the cold and spontaneous pain scores were significantly increased $(\mathrm{p}<0.05)$ (Figure 2).

\subsection{Expression of c-fos in the Spinal Cord}

The expression of c-fos in spinal cord of normal control group, solvent control group, curcumin low dose group, middle dose group and high dose group were detected by immunohistochemical method. The expression of c-fos in cancer pain model group was significantly higher than that in normal control group ( $\mathrm{p}$ $<0.05)$. The expression of $\mathrm{c}$-fos decreased gradually with the increase of curcumin dose, among which the expression of $\mathrm{c}$-fos in high dose group was significantly lower than that in solvent model group $(\mathrm{p}=0.04)$ (Figure 3 ).

\subsection{Expression of RANK, NF- $\mathrm{BB}$, TNF- $\alpha$ by RT-PCR}

The expression of RANK, NF- $\kappa$ B and TNF- $\alpha$ in normal control group, solvent control group, curcumin low dose group, middle dose group and high dose

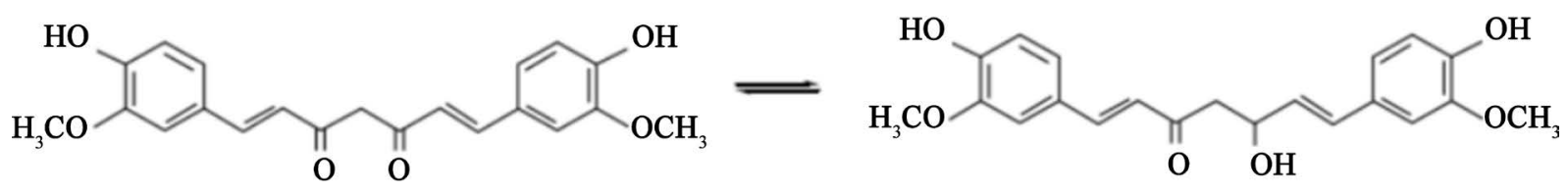

Figure 1. Ways of ketone-enol heterogeneity.

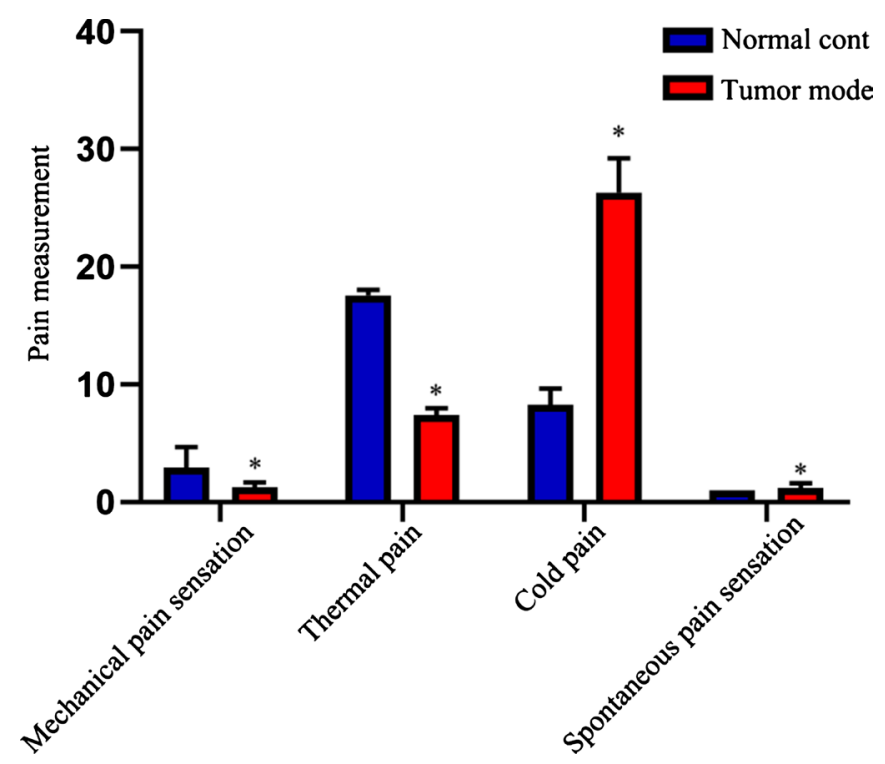

Figure 2. Detection of mechanical pain, heat pain, cold pain and spontaneous pain. 
group were detected by RT-PCR. the expression of RANK, NF- $\kappa$ B and TNF- $\alpha$ in middle dose group were significantly lower than that in normal control group ( $\mathrm{p}$ $<0.05$ ), and the relative expression of RANK, NF- $\kappa$ B and TNF- $\alpha$ in low dose group were significantly lower than that of solvent group $(\mathrm{p}<0.05)$ (Figure 4$)$.
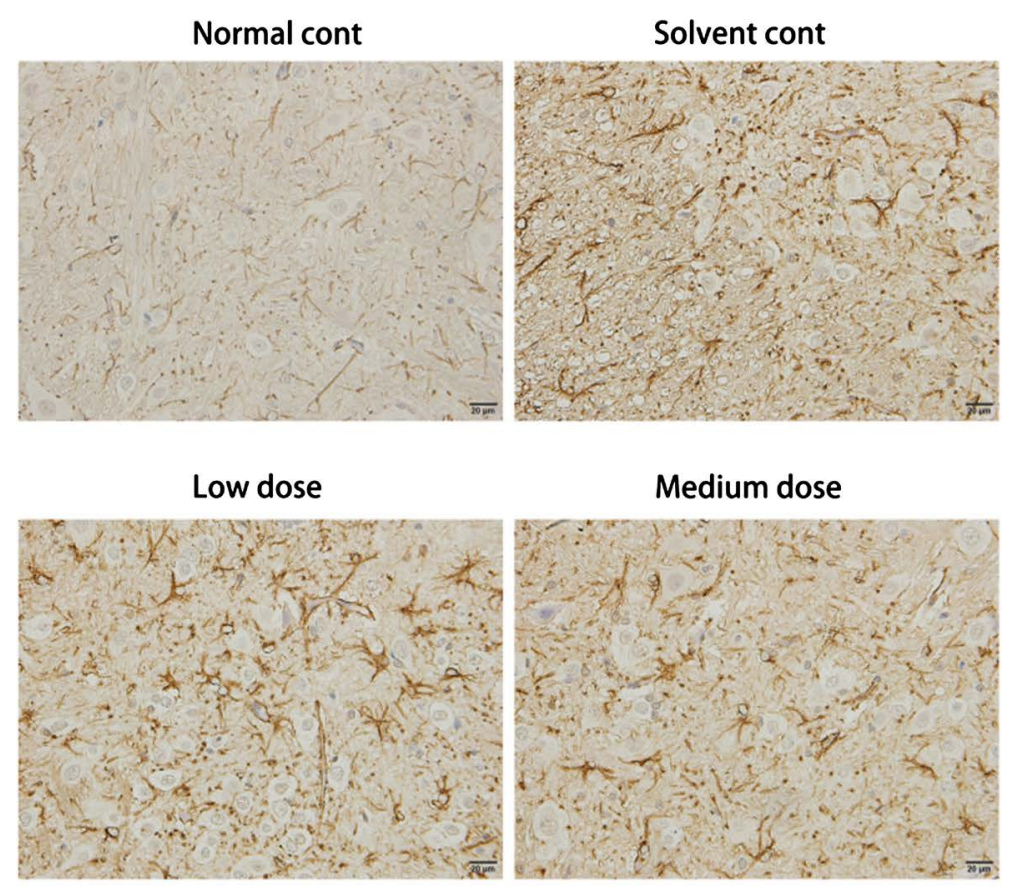

High dose
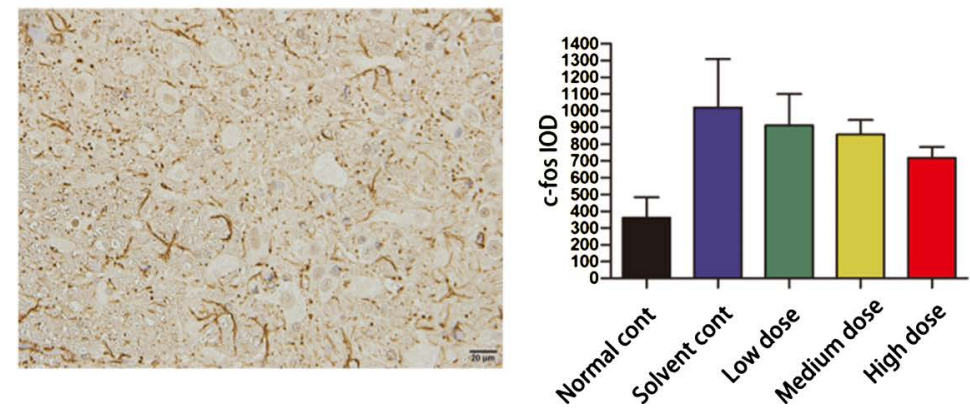

Figure 3. Immunohistochemical analysis of expression of c-fos.
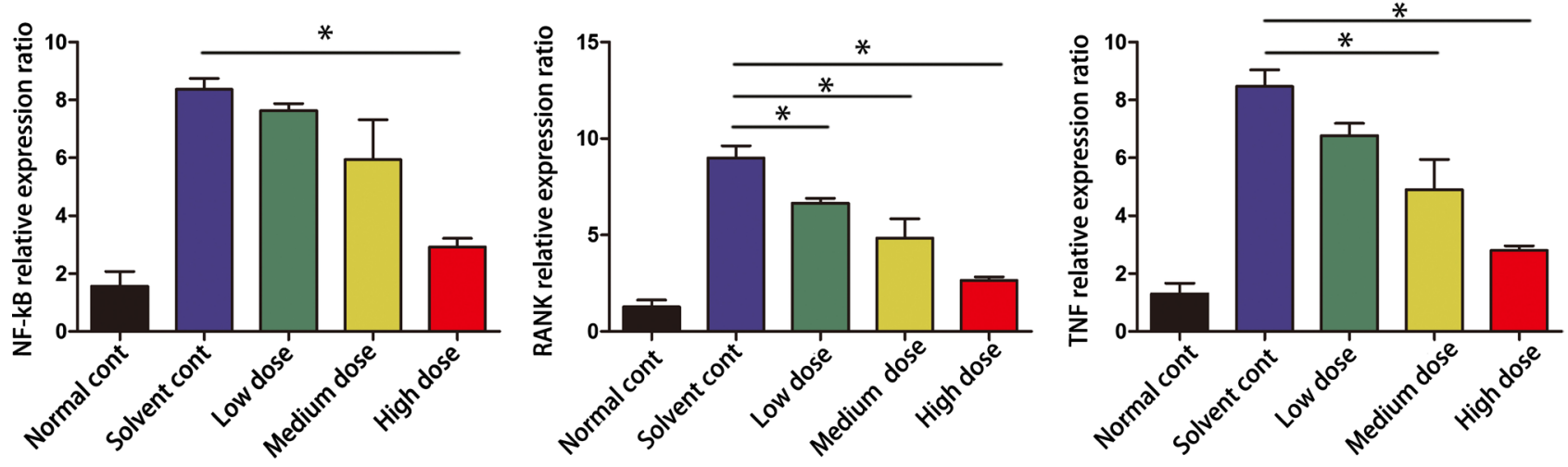

Figure 4. Expression levels of RANK, NF- $\kappa$ B and TNF- $\alpha$ by RT-PCR, ${ }^{*} \mathrm{p}<0.05$. 


\subsection{Expression of RANK, NF- $\kappa B$ and TNF- $\alpha$ by Western Blot}

The expression of RANK, NF- $\kappa$ B and TNF- $\alpha$ protein in normal control group, solvent control group, curcumin low dose group, middle dose group and high dose group were detected by western blot. the expression of RANK, NF- $\kappa \mathrm{B}$ and TNF- $\alpha$ protein in high dose group were significantly lower than that in solvent control group ( $p=0.03, p=0.02, p=0.002)$, and the expression of TNF- $\alpha$ in middle dose group was significantly lower than that in solvent control group (Figure 5).

\subsection{Serum Levels of Cox2, IL-6, Leukotriene and PGE2}

The levels of Cox 2, IL-6, leukotriene and PGE2 in serum of normal control group, solvent control group, curcumin low dose group, middle dose group and high dose group were detected. The study found that the levels of Cox2, il-6, leukotriene and PGE2 decreased continuously with the increase of curcumin dose, Among them, both the medium-dose group and the high-dose group decreased significantly $(\mathrm{p}<0.05)$ (Figure 6).

\section{Discussion}

In recent years, breast cancer had become one of the most malignant tumors with the highest morbidity and mortality in women, which was a serious threat to women's health and life. In view of the biological behavior characteristics of breast cancer, its occurrence and development reflected the multi-factorial role of bio-social-psychological model [3]. Local recurrence and distant metastasis often occur. Bone was the most common metastatic site of breast cancer. The incidence of breast cancer bone metastasis was $70 \%$ to $80 \%$ [5]. $70 \%$ of patients with advanced breast cancer had bone invasion [6], and more than $50 \%$ of advanced breast cancer had bone as the first metastasis site [7]. Therefore, chronic pain caused by bone metastasis was the most common associated symptom in patients with advanced breast cancer. Allodynia was produced by non-nociceptive stimulation; this non-nociceptive stimulation couldn't produce pain in normal physiological conditions. It was one of the important characteristics of pathological

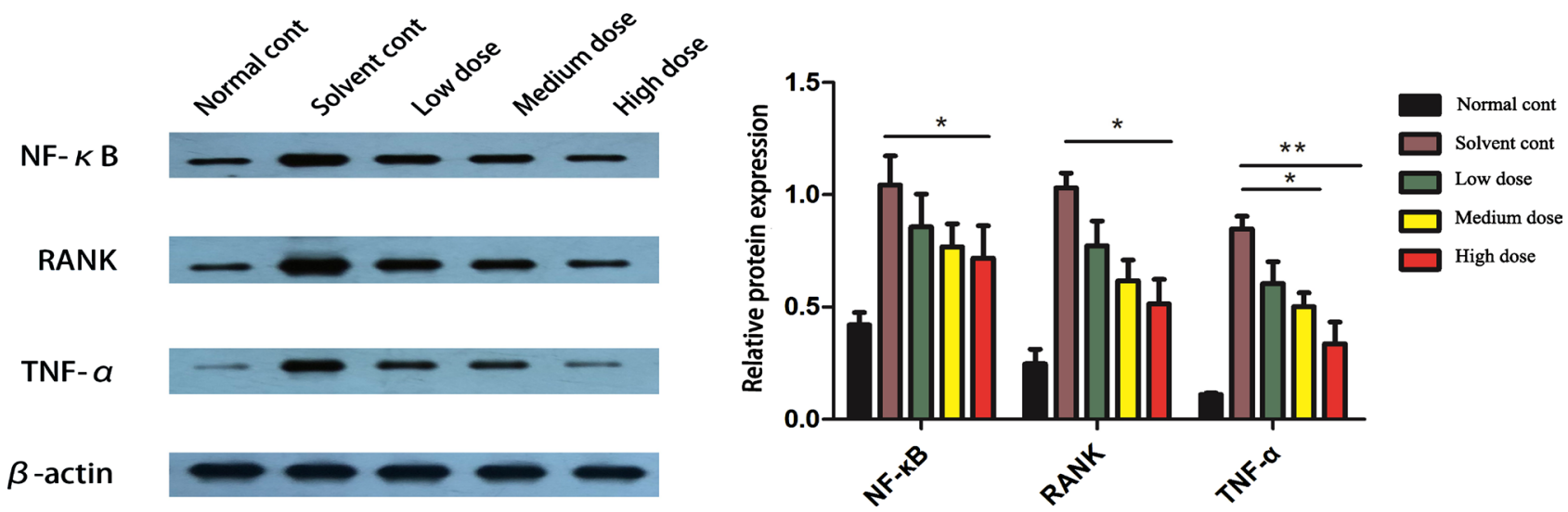

Figure 5. Expression levels of RANK, NF- $\kappa$ B and TNF- $\alpha$ by RT-PCR $\left({ }^{*} \mathrm{p}<0.05,{ }^{* *} \mathrm{p}<0.01\right)$. 

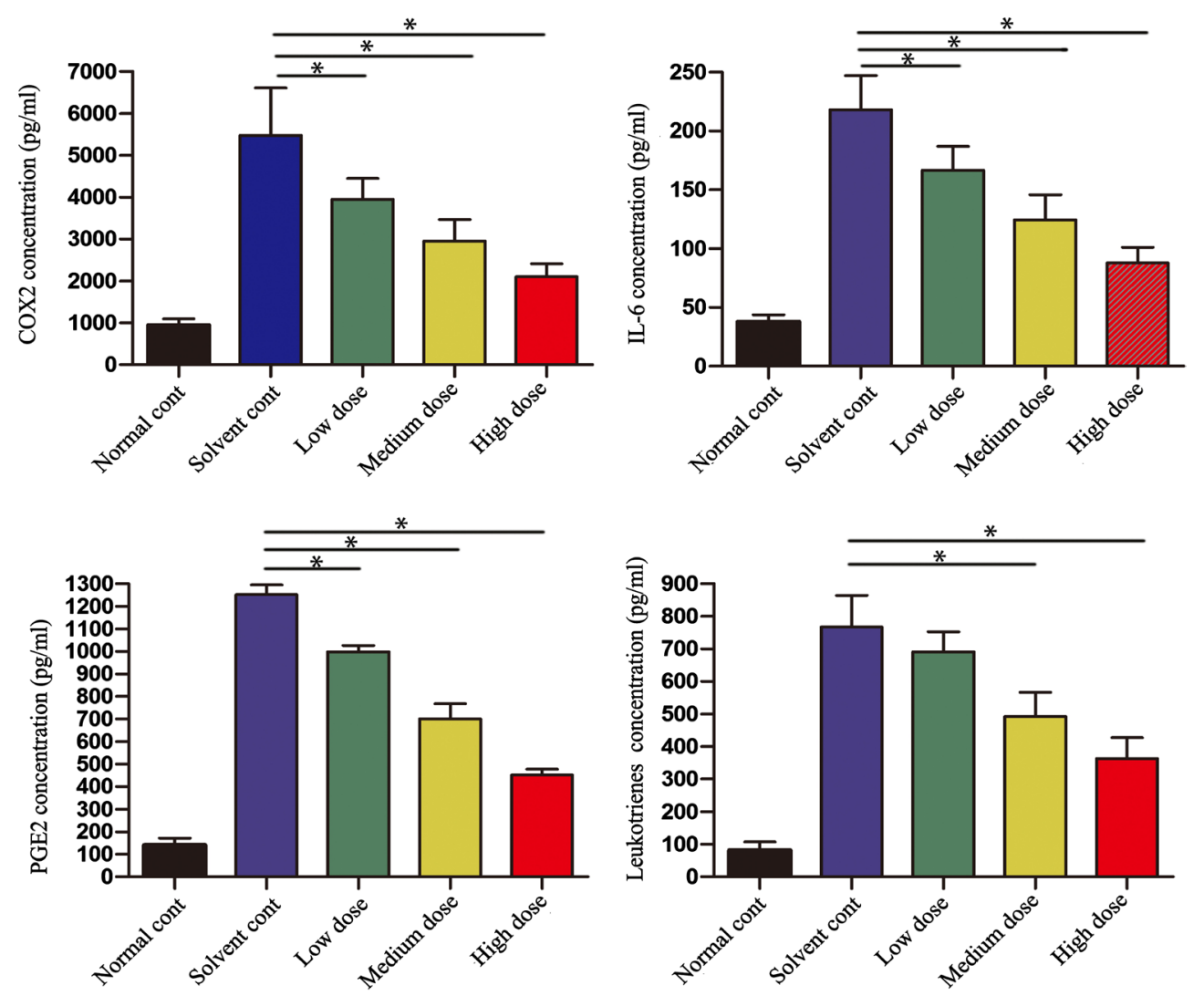

Figure 6. Serum levels of Cox2, IL-6, leukotriene and PGE2.

pain, and it was also an important factor of poor control of bone cancer pain in clinic. Curcumin was the main active ingredient extracted from the base of turmeric. In the study of analgesic effect and its mechanism, some experts believed that curcumin had many effects on physiological function and pathophysiological process of nervous system. It played an analgesic role by reducing the inflammatory response to related inflammatory factors and inhibiting the peripheral or central sensitization of chronic pain.

Once bone metastases occurred in breast cancer, the circulation of bone destruction and woven bone began to initiate and cause significant pain. The receptor activator of NF- $\kappa$ B (RANK) was a member of the TNF receptor family. The combination of RANK with receptor activator for nuclear $\kappa \mathrm{B}$ ligand (RANKL) caused multiple kinase cascades and initiated and transmits signals of osteoclast differentiation [8]. The expression and involvement of cytokines such as downstream NF- $\kappa \mathrm{B}$ and c-fos were needed in the differentiation of osteoclast precursor cells. The combination of RANK with RANKL was a key step in stimulating the activity of NF- $\kappa \mathrm{B}$ [9]. As a transcription factor, nuclear factor-kappab (NF- $\kappa \mathrm{B}$ ) was the convergence point of many signaling pathways and played a key role in regulating inflammatory response [10]. When cells were stimulated by external signals, ikb was phosphorylated and degraded, and NF- $\kappa \mathrm{B}$ was activated into the nucleus, bound to the corresponding parts of the target gene, opened the transcription of related genes, and induced the expression and 
release of genes such as NF- $\kappa \mathrm{B}$, chemokines, inflammatory mediators, etc. [11]. TNF- $\alpha$ was the most important factor of nerve injury and inflammatory response, the earliest released proinflammatory factor. TNF- $\alpha$ was mainly produced by monocyte and macrophage secretion, which showed biochemical characteristics by binding with two receptors TNFR- I and TNFR- II on the cell surface. Some studies had shown that TNF- $\alpha$ expression level was related to acute and chronic joint inflammation and surrounding tissue destruction. The release of TNF- $\alpha$ could reduce the threshold of pain, and thus affect the formation of pain and pain sensitization. The c-fos gene was the most representative immediate early gene in the central nervous system. Under physiological conditions, there were only low levels of expression in many kinds of cells. In the study of pain mechanism, nociceptive stimulation can induce the expression of c-fos protein in different parts of the central nervous system, which was related to the intensity, time and nature of nociceptive stimulation [12].

Compared with the normal control group, the mechanical hyperalgesia threshold, the thermal hyperalgesia threshold decreased $(\mathrm{p}<0.05)$, and the cold pain hyperalgesia and spontaneous hyperalgesia scores increased significantly $(\mathrm{p}<$ 0.05 ) after modeling in this study, which was basically consistent with the results reported in Medhurst SJ et al. [13]. In breast cancer, pain and hyperalgesia occurred soon. Mechanical pain, heat pain, cold pain and spontaneous pain were prominent at first. It is easy to appear hyperalgesia phenomenon and with the extension of time there may be an aggravating trend. The expression of RANK, NF- $\kappa$ B, TNF- $\alpha$ and $c$-fos in the experimental group were higher than those in the normal control group ( $\mathrm{p}<0.05$ ), and the levels of Cox2, IL-6, leukotriene and PGE2 in the serum were also higher than those in the normal control group $(p<0.05)$. It can be speculated that under the nociceptive stimulation of bone metastasis in breast cancer, rank expression on osteoclasts was obvious. After binding to RANKL on osteoblasts, the activity of transcription factor NF- $\kappa \mathrm{B}$ was enhanced, the expression of c-fos in spinal cord was increased, and the transcription of osteoclast-specific gene was initiated by binding to activated NFAT-C. After NF- $\kappa$ B entered the nucleus, it bound to the corresponding site of the target gene, opened the transcription of the related gene, and induced the expression of multiple cytokines TNF- $\alpha$ gene. TNF- $\alpha$ can activate cyclooxygenase by direct activation of cyclooxygenase, inflammatory mediator IL- 6 cascade reaction, promoted the formation of leukotriene and accelerated the synthesis and release of prostaglandin e2 (PGE2), thus produced pathological pain and hyperalgesia sensitization.

After intraperitoneal injection of $15 \mathrm{mg} / \mathrm{kg}, 25 \mathrm{mg} / \mathrm{kg}$ and $50 \mathrm{mg} / \mathrm{kg}$ of curcumin solution in low dose group, middle dose group and high dose group, the expression of RNK, NF- $\kappa \mathrm{B}$, TNF- $\alpha$ and spinal cord $\mathrm{c}$-fos in high dose group was decreased gradually with the increase of curcumin dose in nude mice $(\mathrm{p}<0.05)$. The expression of spinal cord $c$-fos in high dose group was significantly lower than that in solvent group $(\mathrm{p}<0.05)$. The levels of Cox 2 , IL-6, leukotriene and 
PGE2 in serum were detected. The levels of Cox2, IL-6, leukotriene and PGE2 decreased with the increase of curcumin dose $(\mathrm{p}<0.05)$. Among them, the middle dose group and the high dose group decreased significantly $(\mathrm{p}<0.05)$. From this, it can be seen that curcumin especially $25 \mathrm{mg} / \mathrm{kg}, 50 \mathrm{mg} / \mathrm{kg}$ curcumin solution can inhibit the activity of cell NF- $\kappa \mathrm{B}$ and spinal cord c-fos by reducing the expression of osteoclast rank, thus reducing the expression of TNF- $\alpha$ and the release of inflammatory factor PGE2, while further reduced the formation of important inflammatory factor PGE2 in bone pain by reducing the production of leukotriene and inhibiting the activity of Cox2. It can be speculated that this may be a possible mechanism for curcumin to exert an analgesic effect on bone metastasis pain in breast cancer.

\section{Conclusion}

In this paper, by establishing the animal model of metastatic bone cancer and observing the biological behavioral changes of the experimental animals, we explored the mechanism of metastatic bone pain and sensitization in breast cancer from histological molecular level, and used the modern medical experimental method to select the active ingredient curcumin of traditional Chinese medicine for intervention study, which provided a new way to control the bone metastatic pain effectively. However, the pathological mechanisms of bone metastases were complex and the pathways involved in this study, whether curcumin has direct effect or indirect effect, still need to be supported by other methods. Whether curcumin can be applied directly to the clinical treatment of bone metastases, whether it can be used in combination with clinical treatment, whether it can effectively reduce the toxic effect of long-term drug treatment, how it can be applied safely and so on, these series of issues need our more in-depth study.

\section{Data Availability}

Data are available regarding this study.

\section{Acknowledgements}

The article comes from Jiangsu province high-level health personnel "six one project" top talent scientific research project (code: LGY2018068)

\section{Conflicts of Interest}

The authors declare no conflicts of interest regarding the publication of this paper.

\section{References}

[1] Zhou, J.J., Zheng, Y.C., Li, M.Y., et al. (2016) Progress in Pharmacological Action of Curcumin. Journal of Jilin Institute of Medicine, No. 4, 304-307.

[2] Kapoor, S. (2012) Curcumin and Its Emerging Role in Pain Modulation and Pain Management. Korean Journal of Pain, 25, 202-203. 
https://doi.org/10.3344/kjp.2012.25.3.202

[3] Anand, P., Kunnumakkara, A.B., Newman, R.A., et al. (2007) Bioavailability of Curcumin: Problems and Promises. Molecular Pharmaceutics, 4, 807-818. https://doi.org/10.1021/mp700113r

[4] Priyadarsini, K.I. (2009) ChemInform Abstract: Photophysics, Photochemistry and Photobiology of Curcumin: Studies from Organic Solutions, Biomimetics and Living Cells. Journal of Photochemistry \& Photobiology C Photochemistry Reviews, 10, 81-95. https://doi.org/10.1016/j.jphotochemrev.2009.05.001

[5] Wang, Y.S., Wu, J., Yu, J.M., et al. (2012) Mastology. 4th Edition. Shandong Science and Technology Press, Ji'nan, $1527 \mathrm{p}$.

[6] Jemal, A., Siegel, R., Xu, J., et al. (2010) Cancer Statistics. CA: A Cancer Journal for Clinicians, 60, 277-300. https://doi.org/10.3322/caac.20073

[7] Zhang, L., Hou, N., Xiang, Y., et al. (2015) Research Progress in Analgesic Effects of Curcumin. Medical Recapitulate, 21, 2986.

[8] Li, X., Zhou, Y.M., Ma, S.S., et al. (2016) Role of RANK-RANKL-OPG Singaling Pathway in Bone Remodeling. Journal of Oral Science Research, 32, 659-662.

[9] Darnay, B.G., Haridas, V., Ni, J., et al. (1998) Characterization of the intracellular Domin of Receptou Activator of NF-kappaB (RANK). Interaction with Tumor Necrosis Factor Receptor-Associated Factors and Activation of NF-kappaB and c-Jun N-Terminal Kinase. Journal of Biological Chemistry, 273, 205551-220555. https://doi.org/10.1074/jbc.273.32.20551

[10] zhuni. (2011) Research Progress of Nuclear Transcription Factor NF-k B and Its Inhibitors. Chinese Journal of Biological Products, 24, 869-872.

[11] Foo, S.Y. and Nolan, G.P. (1999) NF-KB to the Rescue: R ELs, Apoptosis and Cellular Transform Ation. Trends in Genetics, 15, 229-235.

https://doi.org/10.1016/s0168-9525(99)01719-9

[12] Zhang, Z.Q., Zhao, B.M. and Geng, X.S. (2012) Advances in Molecular Biology of Pain Sensitivity. Shanghai Medicine, 35, 914-917.

[13] Medhurst, S.J., Walker, K., Bowes, M., et al. (2002) A Rat Model of Bone Cancer Pain. Pain, 96, 129. 